\title{
Solvency II and the Work of CEIOPS
}

\section{Thomas Steffen}

CEIOPS, Westhafenplatz 1, 60327 Frankfurt am Main, Germany.

E-mail: Thomas.Steffen@bafin.de

This paper by the Committee of European Insurance and Occupational Pensions Supervisors' (CEIOPS) Chair gives an overview of the main current features of the Solvency II project and CEIOPS work on it, at the time of writing (September 2007). After a brief summary of reasons, drivers and objectives for the proposed new regime, some of the details are described, in terms of CEIOPS' published Advice to the European Commission. Technical provisions, consistency with International Accounting Standards Board, and lead aspects of the three Pillars - solvency capital requirements, minimum capital requirements, internal models, qualitative criteria, supervisory review process, disclosure - are mentioned. CEIOPS' Qualitative Impact Studies are then outlined. The paper concludes with some open political issues.

The Geneva Papers (2008) 33, 60-65. doi:10.1057/palgrave.gpp.2510162

Keywords: solvency II; directive; CEIOPS; risk-sensitive; QIS; pensions

A paper outlining the key features of Solvency II and the Committee of European Insurance and Occupational Pensions Supervisors' (CEIOPS) work is highly appropriate for a journal titled Issues and Practice. Those of us involved with the Solvency II project are working hard to combine new conceptual issues with their practical application, both by the industry and supervisors.

For readers not fully familiar with the current European union (EU) prudential regime for insurance, it may help to explain first some of the reasons for change.

It is probably known that there are three main EU Insurance Directives, while it may be less apparent that there is minimum harmonization between them. They leave considerable room for the exercise of national discretion. The characteristic is not unique to insurance legislation in the EU. The Solvency II project presents an opportunity to enhance appropriate harmonization, within insurance and to an extent outward across other financial sectors.

The present regime has a limited degree of risk sensitiveness and implicit limits. At the time it was developed, during the latter half of the last century, agreed practice used comparatively formulaic applications. They are considered historic for the 21 st century's financial players and markets. It is now time for a more risk-sensitive regime for all.

Presently, there are only general references to sound internal control and governance. Major instances where these are considered to have fallen short of expectations have attracted high publicity. Their importance in financial institutions is increasingly recognized and expected and this is being addressed as a key part of the Solvency II project.

Accounting practices often support the prudential supervision of insurance business. Currently, there can be inconsistencies with what we know to be the economic reality of given situations. Work to align these better is also in hand. 
On insurance groups' supervision, our system is based on a "solo plus" approach rather than a group one. The requirements are largely out of step with the way many insurance groups organize themselves and actually operate. It is one of the more sensitive issues in Solvency II, but there are proposals for alternatives.

Given the motivation for change, what are its main drivers? Inevitably in work of this scale and complexity, they involve the balancing of differing key objectives.

Strengthening consumer protection is called for. Many EU national financial supervisory bodies are the ones primarily responsible for consumer interests while others are not; consumer protection and confidence is clearly a priority in any newly devised prudential regime. It is at the heart of this one.

Fostering the EU internal market for financial products remains a crucial European target. Solvency II is aimed at possible improvements for insurance products towards this end.

There are industry-focused objectives for Solvency II. They include seeking to increase competitiveness. At the same time a responsible system should support fair competition between different types of players, for example, between the larger insurance groups and smaller or medium-sized undertakings.

Financial stability naturally has to be enhanced rather than put at risk. Although obvious as a mission statement, carrying it through to an innovative insurance project like Solvency II is sometimes challenging.

All these objectives are thought to be compatible with gaining a maximum level of EU harmonization. As usual the devil is in the detail. It is causing many interesting debates.

Moving on to some of that detail, it may be best described in this paper through the main aspects of CEIOPS' published Advice to the EU Commission. The Commission has recently published the draft proposal with the text for a Solvency II Directive that is subject to negotiation and possible change at the political level.

As main headlines, it should be no surprise to learn that one of the most difficult areas to find consensus on has been that of technical provisions. They are sometimes said to be more political than technical. Compromises achieved within CEIOPS have included using market consistent valuation where possible, so as to make optimal use of market information. This means using market values where risks can be hedged in deep liquid and transparent markets. In other circumstances, best estimate including discounting should be calculated, added to by an explicit risk margin according to the so-called cost of capital approach. Realistic assumptions for the best estimate should be employed, such as no surrender value, or the inclusion of all future expenses and costs, including inflation.

Another principal work-stream is CEIOPS' constant assessment of consistency between its advice and the ongoing work of the International Accounting Standards Board (IASB) in London. So far the consistency level is high. As supervisors, CEIOPS is much in favour of supervisory reporting based on financial reporting and economic realities. Therefore CEIOPS' view is that as an over-riding principle, the methodologies for calculating items in general purpose financial reports should be used for, or be substantially consistent with, the methodologies used for supervisory reporting. Part of the principle is that prudential filters should be limited as far as possible. 
Following on from that, CEIOPS sees a possible need for application guidance. Because of the complexities involved in measuring insurance liabilities, together with the fact that the IASB Phase II standard is unlikely to be prescriptive, application guidance might be called for to facilitate consistency and convergence, as well as to support the usability of IFRS as a base for assessing solvency. An appropriate balance will have to be struck between a practical need for guidance and the upholding of an IFRS principle-based approach.

CEIOPS' commitment to monitor and influence IASB's work through its group dealing with accounting and reporting can be understood in this light. The IASB's Phase II Discussion Paper on accounting for Insurance Contracts, with its three building blocks for a valuation model for insurance liabilities, is being carefully scrutinized. CEIOPS had already commented on the IASB Discussion Paper on Fair Value Measurement. This is important in view of CEIOPS' support for a market consistent valuation of assets and liabilities under Solvency II.

After these headlines come the specifics. Much of these fall under Pillar I.

Work on the solvency capital requirements (SCR) and minimum capital requirement (MCR) has been publicly analysed as it has progressed. The SCR is central to the new regime. It is based on a "non-zero failure" assumption in the Commission's framework for consultation. To paraphrase the Commission there: "The SCR should deliver a level of capital that enables an insurance undertaking to absorb significant unforeseen losses over a specified time horizon and give reasonable assurance to policyholders that payments will be made as they fall due." ${ }^{\text {Th }}$ The SCR is calculated on a 99.5 per cent confidence level over 1 year.

Together with the rest of CEIOPS' advice on the SCR, the recommendation has been to have an additional MCR. The MCR should be easy to calculate. Breaches should lead to ultimate supervisory action.

One option to calculate future capital requirements is the SCR standard formula. CEIOPS' advised modular approach of the SCR standard formula consists of six main risk modules and 18 sub-modules, either factor or scenario based, and also including additional correlation factors between the single risk modules (see Figure 1).

Other options are that the SCR can also be based on a full or partial internal model. These will give a high degree of freedom to companies to reflect their individual risk situation and calculate the capital buffer needed on their own. Supervisors will then validate the outcome of the modelling, rather than prescribe the input for modelling. Reflecting the individual risk situation should normally lead to a lower capital requirement compared with the standard formula that could also under some circumstances lead to higher capital requirements if risks are high.

Pillar I cannot of course be isolated from Pillars II and III. The qualitative criteria and review processes for undertakings and their supervisors under Pillar II, together with the reporting and disclosure provisions under Pillar II, have to form a coherent workable whole. Without listing them all, a diagrammatic representation can give some indication of their inter-relationships (see Figure 2).

\footnotetext{
${ }^{1}$ European Commission (2005).
} 


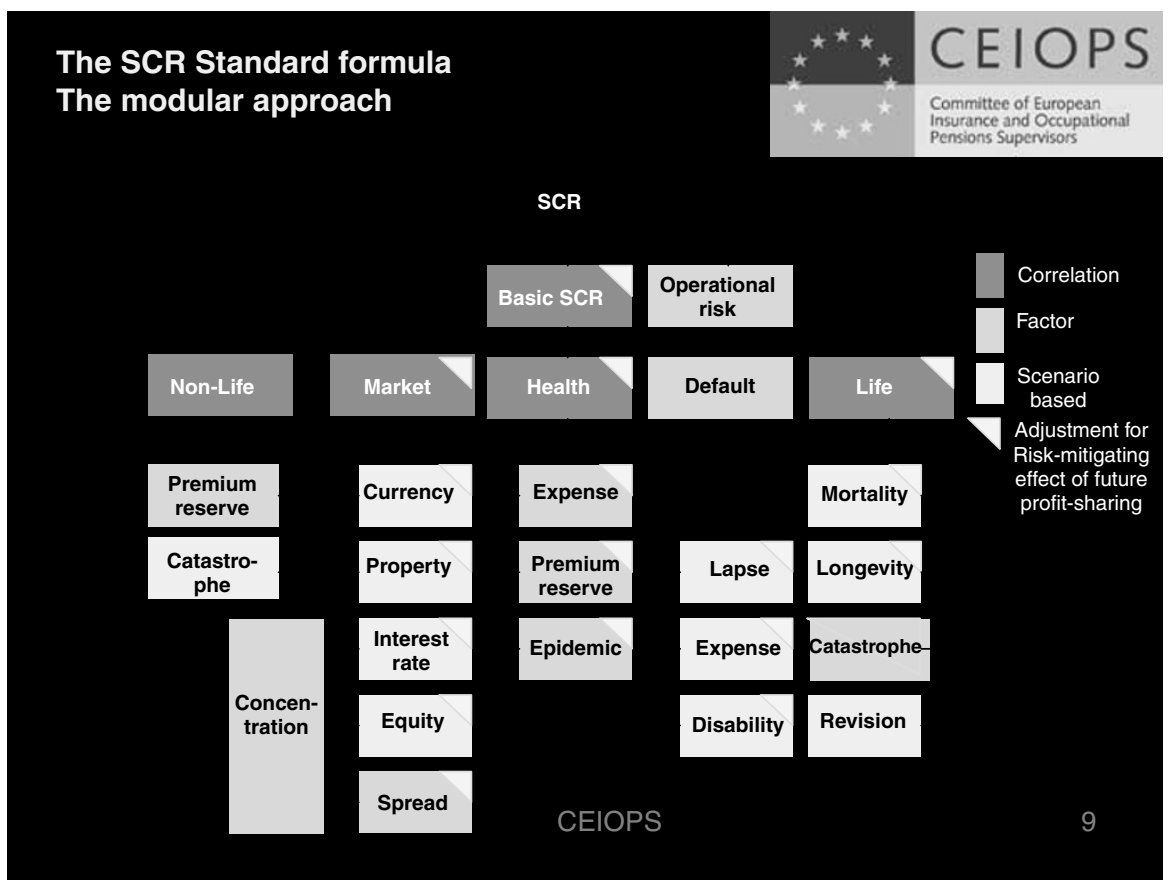

Figure 1. SCR standard formula, modular approach.

Another endorsement of CEIOPS combining "Issues and Practice" is its fieldtesting exercises (Qualitative Impact Studies, or QIS). These have been based on similar exercises for the banking sector under Basel II. However, where bankers were faced with five impact assessments, in view of the greater complexity of insurance and of new approaches beyond Basel II, Solvency II may warrant five or even six QIS.

The latest to have been carried out is QIS3, which was the first calibration exercise. It also attracted a high participation rate by the industry, which is crucial to its success. The testing covered the impact on undertakings' balance sheets, the practicality and suitability of calculations, the suitability of tentative calibrations, and importantly the impact at group level including diversification.

The main pending issues for QIS3 are the relation between the SCR and MCR, the calibration of the standard formula and internal models, the calculation of equity and property risk charge, and the treatment of free assets. At the time of writing this paper, CEIOPS' QIS3 Report is intended for publication mid-November 2007.

CEIOPS is constantly seeking to improve the field tests by building on its experience. The general approach is to limit the burden on industry. Methods include the minimum of options and double calculations, a reduction in complexity, and better explanations of the underlying rationale. Part of the objective is to encourage smaller and medium-sized entities to participate. They may do so on a "best effort" basis. 


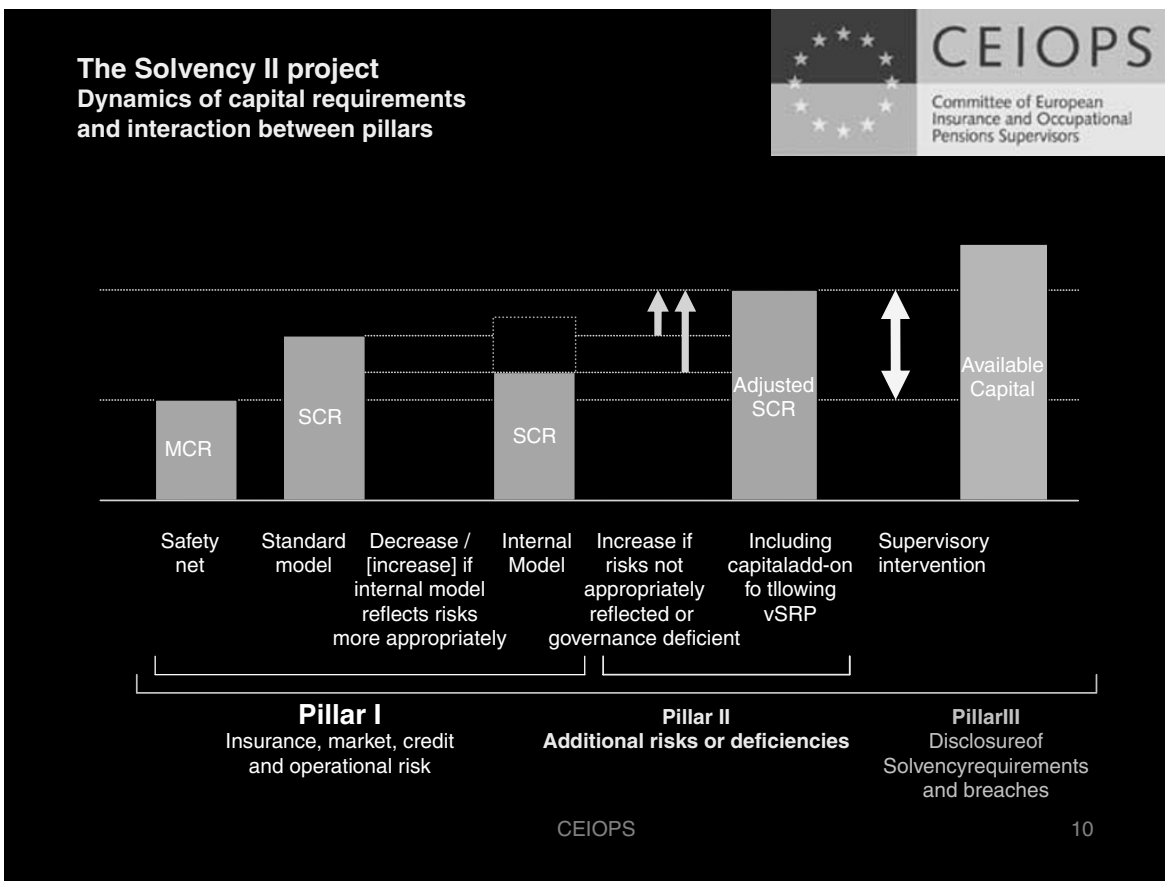

Figure 2. Solvency II, interaction between Pillars.

To conclude, Solvency II has some pending political issues.

There is the position of smaller companies. They may be given exemptions below certain thresholds and may be granted simplifications of the SCR calculation. The fundamental principle of proportionality will come into play for them.

There is also an unresolved approach to insurance groups supervision. CEIOPS' advice to the EU Commission based on the current framework for consultation has already been towards further strengthening the group supervisor's role. CEIOPS has included limiting sub-group supervision and recognizing diversification effects. A "new group supervision" proposal has been presented at Level 2 of the EU institutions and will be negotiated at the political levels of EU Council and EU Parliament. CEIOPS is at the same time eager to support these negotiations to the extent possible and give further advice on any new proposal, bringing in the interests of major groups as well as the interests of customers on a solo and national level. As was said under key Solvency II objectives to be reconciled, strengthening customer confidence in financial markets is at the heart of the whole project.

Lastly, for present purposes, there is the whole question of occupational pensions. While they are beyond the current scope of Solvency II, there may possibly be a future EU review initiative in their direction.

So Solvency II and CEIOPS' work on it have come a long way. They are far from nearing completion. If future tasks are as interesting and challenging as those of the 
past, the insurance world will remain a focus of attention and of CEIOPS' efforts for some time to come.

\title{
Reference
}

European Commission (2005) Amended Framework for Consultation on Solvency II, Brussels: European Commission (July).

\begin{abstract}
About the Author
Thomas Steffen joined the Conference of European Insurance Supervisors when he became BaFin's (Federal Financial Supervisory Authority) Chief Executive Director of insurance supervision in October 2002. Before, he was head of section in the Federal Ministry of Finance where he was responsible for the Government's Export Credit Insurance and state guarantees in the federal budget. From 1995 onwards he has been working in various financial policy-related areas of the Federal Ministry of Finance including also a 2-year secondment to the German Parliament. Thomas Steffen started his professional career in 1990 when he joined the Federal Ministry of Economics where he worked in the Industrial policy and the European Department including a 1 year secondment to the Federal Trust agency for the privatization of holdings and assets in Eastern Germany and a 1 year stage in a regional Ministry of Finance as head of section in the assets department. Thomas Steffen has a degree in law and political science. From 1989 to 1991 he did his doctorate in comparative law at the University of Mainz following studies at the London School of Economics and Political Science in London.
\end{abstract}

